\title{
LA ELEGÍA FÚNEBRE COLONIAL: CARLOS III Y LA RETÓRICA DEL LAMENTO (Parte I)
}

\author{
The Colonial Funeral Elegy: Carlos III and the Rhetoric of Mourn (Part I)
}

\author{
Sebastián Altamirano Pacheco*
}

\section{RESUMEN}

La investigación consiste en un acercamiento a las elegías latinas presentes en el texto Descripción de las reales exequias a la tierna memoria de Carlos III (1789) con el propósito de identificar, precisamente, los elementos elegíacos en relación, asimismo, con el discurso latino de la laudatio funebris desde la teoría retórica clásica. El marco teórico consiste en la preceptiva retórica de Anaxímenes de Lámpsaco, Aristóteles, Rhetorica ad Herennium, Menandro el Rhetor, Theón, Hermógenes de Tarso y Aftonio.

Palabras clave: Querimonia, monodia, epidíctico, laudatio, Carlos III.

\begin{abstract}
The investigation bases on the Latin elegies from the article: Description of the real funeral to the dearest memory of Carlos III (1789), which seeks to identify, precisely, the elegiac elements related to the Latin speech of the laudatio funebris from the rhetorical classical theory. The theoretical framework consists on the rhetorical perceptive from Anaximenes from Lampsacus, Aristotle, Rhetorica ad Herennium, Menander Rhetor, Theon, Hermogenes of Tarsus, and Aphthonius.
\end{abstract}

Key Words: Querimonia, monodia, epidíctico, laudatio, Carlos III.

\footnotetext{
* Universidad de Costa Rica. Departamento de Filología Clásica, filólogo clásico. Costa Rica. Correo electrónico: sebassho@yahoo.es
} 


\section{Introducción}

El propósito de la investigación es identificar los rasgos propios de la elegía fúnebre latina en el texto Descripción de las reales exequias a la tierna memoria de Carlos III (1789) en comparación con la retórica clásica. Como objetivo específico, además del citado, se procura explicar el vínculo entre la elegía fúnebre y la retórica clásica; asimismo, examinar la presencia de los rasgos elegíacos y su función pragmática con la situación histórica.

Con base en lo anterior, se definió como corpus para la investigación el poema Elegia 2, ya que el poema Elegia 3 será el corpus para la segunda parte. El propósito es el análisis del texto latino per se y, tras una lectura de la obra, solo se hallaron estos dos como los únicos en este idioma que son contemplados como elegías en la obra según la denominación en el encabezado textual.

Así, ya mencionado el motivo de la investigación y el corpus, se procede a reseñar, primeramente, algunos aspectos de la vida del personaje a quien se compuso la obra, el rey Carlos III; seguidamente, los preceptos teóricos de la retórica clásica; a continuación, el rol pragmático que tiene el texto y, finalmente, el vínculo entre el aspecto fúnebre y la retórica a partir del tema del lamento como principal eje argumentativo.

\section{Carlos III}

Carlos III nació el 20 de enero de 1716 y murió el 14 de diciembre de 1788. Entre sus títulos se destaca que ejerció como duque de Parma y Plasencia (1731-1735), a posteriori como rey de Nápoles y Sicilia (1734-1759) y, el más célebre y reconocido, como rey de 
España desde 1759 (10 de agosto) hasta su fallecimiento en 1788, con 72 años. Fue enterrado en la Cripta Real del Monasterio de El Escorial.

Sobre este personaje, a quien se dedican las honras fúnebres, se enumeran los siguientes hechos relevantes de su vida:

a) fue conocido como "el Político";

b) contrajo matrimonio en 1738 con María Amalia de Sajonia, hija de Federico Augusto II (duque de Sajonia y Lituania, rey de Polonia);

c) su predecesor fue Fernando VI y su sucesor Carlos IV;

d) la consecuencia del Tratado de Sevilla (1729), con Inglaterra y Francia, la cual provoca que en 1731, con 15 años edad, deba abandonar España y dirigirse a Italia; e) su aporte arqueológico, ya que ordenó excavaciones de poblaciones sepultadas por la erupción del Vesubio (79 d. C.): Pompeya, Herculano, entre otras;

f) la razón de su coronamiento: por muerte sin descendencia de su medio hermano Fernando VI;

g) la Guerra de los Siete Años (1754-1763), intervención española (1761) en América para frenar el expansionismo británico por América;

h) la Guerra de Independencia de los Estados Unidos (1775-1783), intervino junto a Francia contra Gran Bretaña;

i) entre sus ministros destacan el Marqués de Esquilache, Aranda, Campomanes, Floridablanca, Grimaldi, entre otros;

j) su muerte, próxima a la Revolución Francesa; 
k) su participación en la creación de los símbolos de identidad (himno y bandera), su labor al modernizar Madrid con la Puerta de Alcalá (sustituye una anterior de siglo XVI) o el Museo del Prado, entre otros;

l) durante su gobierno se presentó la expulsión de los jesuitas de España (1767), así como el hecho de los instigadores de motines (Motín de Esquilache).

De lo anterior se colige que los hechos citados son ejemplo de la inuentio retórica para su encomio. Las acciones que realizó o en las que participó Carlos III son la base para hallar las piezas que conformaran el elogio a su figura. Los hechos comparten aspectos relevantes para la historia de España, así como la conexión con otros sucesos trascendentales en el mundo occidental, casos de la Revolución Francesa o las guerras de independencia de algunas colonias.

La retórica epidíctica, a la cual compete este propósito argumentativo, exhibe diversos géneros que pueden tomar las acciones citadasy utilizarlas como argumentos para elogiar al recién fallecido. Los tres géneros fúnebres contemplados en la investigación paramythētikós, epitáphios y monōidía-comparten el elemento de encomio en su base argumentativa, de manera que confluyen en exponer cualidades del difunto. A partir de ahora, las referencias sobre estos tres géneros serán, respectivamente, consolación, epitafio y monodia.

El discurso epidíctico abarca distintos enfoques según predomine temáticamente en cada composición. Las acciones del individuo que recibirá el encomio son el material a partir del cual comienza a tomar forma el discurso de corte laudatorio. 


\section{El discurso epidícito y la laudatio funebris}

La retórica clásica contempla tres géneros principales que se erigen como base elemental para su concepción teórica. El primero de ellos es el conocido como deliberativo o político, en el cual se utiliza el discurso para resaltar la conveniencia que tiene o no una acción en particular, de manera que apela a un tiempo futuro, ya que se procura influir en el presente para que se tome la decisión en cuestión de horas o días. El segundo corresponde al judicial o forense, en donde la atención se centra en demostrar la inocencia o culpa de un sujeto en algún hecho concreto, de modo que se sustenta en un tiempo pretérito, puesto que la acción que ocasiona la respectiva acusación ya ha concluido.

El genus epidíctico, el tercer género retórico, se caracteriza por el tiempo presente, los medios de elogio y censura y los fines de lo bello y lo feo. Según el teórico griego Anaxímenes de Lámpsaco, las especies que lo abarcan son la laudatoria y la vituperación. El caso de la primera es el que ocupa la investigación, pues comprende el enunciado lingüístico cuyo fin es destacar las acciones, cualidades o características de un individuo concreto que son dignas de respeto y admiración; su contraparte, la vituperación, procura exhibir, por el contrario, las cualidades negativas de un individuo u objeto.

Vale acotar, para efectos del presente artículo, que la terminología clásica entiende el

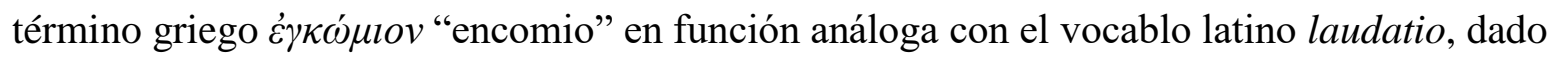
que ambos apelan a la expresión de palabras dignas de elogio o loa, pues el primero proviene del sustantivo griego $\kappa \tilde{\omega} \mu о \varsigma$, que refiere a una procesión festiva, y el segundo del verbo laudo, cuyo significado es elogiar, alabar, enaltecer.

Por su parte, Hermógenes de Tarso (160 d. C.) define "encomio" como "exposición de cualidades que alguien posee en común (ejemplo: el hombre) o individualmente (ejemplo: 
Sócrates)" (1991, p. 187). Asimismo, el rétor griego indica la diferencia con la alabanza en que esta es de pocas palabras (ejemplo: Sócrates es sabio), mientras que el encomio es más extenso. Desde un aporte histórico para el origen del término, Hermógenes confirma su procedencia de las ceremonias festivas al detallar que se halla en los poetas que cantaban himnos a dioses en las aldeas (kómai).

En línea con lo anterior, Aftonio de Antioquía define encomio como "composición expositiva de cualidades propias de alguien" (1991, p. 236). Acota que difiere del himno en tanto este es propio de dioses y el encomio de mortales. Además, señala que la alabanza es breve y el encomio debe ser más extenso, tal como indicó Hermógenes.

Con respecto a la estructura del encomio, Aftonio la ubica de la siguiente manera: proemio de acuerdo con el tema existente; luego linaje (pueblo, patria, antepasados, padres); educación (ocupaciones, dominio del arte y respeto de las leyes); acciones (espíritu -valor o prudencia-, cuerpo - belleza, rapidez y fuerza-, y fortuna - poder, riquezas y amigos-; luego comparación y epílogo (súplica) (1991, pp. 236-237).

Theón, "el estoico” según Quintiliano, define encomio como "composición que pone de manifiesto grandeza de acciones nobles y otras cualidades de personaje determinado" (1991, p. 124). Un aspecto determinante es señalado por Theón, la distinción esencial en cuanto a cómo en su época (s. I d. C.) el encomio se componía para los vivos y el epitafio para los muertos, pero ambos utilizaban el mismo método argumentativo basado en tres aspectos: a) espíritu y carácter; b) cuerpo (fuerza, salud); c) cosas externas (nobleza).

En cuanto a la variedad de tipología de discursos de carácter epidíctico, Menandro Rhétor (1996) expone diversos tipos. Sin embargo, para la investigación son útiles los siguientes tres: 
a) paramythētikós (consolación): Se recomienda que el orador también se lamente por el fallecido, que magnifique la desgracia que provoca su muerte y amplifique la emoción en el discurso, a partir de los puntos de la monodia (p. 216). En la segunda parte del discurso es donde se ejecuta propiamente la consolación (p. 217) y se sugiere que la extensión sea moderada (p. 219).

b) epitáphios (epitafio): Corresponde al elogio del fallecido. Su origen proviene de Atenas, donde cada año, en la tumba del difunto, se pronunciaba un discurso en honor de los caídos en combate (p. 224). Menandro Rhétor acota que se convirtió en encomio por haber pasado mucho tiempo, y cita un aporte destacado de Tucídides tras incluir el tópico de la consolación en lugar del de "lamento por necesidad de guerra", el cual procuró evitar (p. 225). En este tipo son más importantes las acciones y cuando se elogia la naturaleza del individuo deben citarse según la belleza del cuerpo y los dotes del alma (p. 227).

c) monōidía (monodia): Consiste en el lamento unido al acto de compadecerse por el deceso del difunto. Sobre el propósito de la monodia, Menandro Rhétor afirma:

Lamentarse y compadecerse: en el caso de que el muerto no sea un pariente, sólo lamentarse por el que se ha ido, mezclando encomios con los [20] lamentos, y expresar constantemente el lamento, para que no sea meramente un encomio, sino que el encomio sirva de pretexto para el lamento; pero, en el caso de que sea un pariente, además de lamentarse, también se compadecerá el orador de sí mismo, bien por haber quedado huérfano, bien por haber sido privado de un padre excelente y estar llorando él por su propia desolación. Si acaso el difunto fuera un prohombre de 
una ciudad, dirás algo también sobre la ciudad misma, empleando los encomios de ella en relación con el tema (p. 247).

De lo anterior se colige, como factor notable, la cercanía que se tuviera con el difunto para iniciar la argumentación, pues, como bien señala Menandro Rhétor (1996), la queja es necesaria al comienzo del discurso para enfocarse en lo inmediato, es decir, la nueva vida sin el fallecido (p. 248). La queja, propiamente, se dirigía a las divinidades, de modo que la cercanía entre el orador y el difunto otorga mayor fuerza argumentativa a ese lamento contra un "hado injusto".

Es relevante apuntar que las monodias deben pronunciarse en honor de jóvenes y no para los ancianos, de modo que es determinante la edad del difunto. Este aspecto calza muy bien con la estructura, puesto que, en cuanto a esta, es importante la división que hace de la monodia en tres tiempos: presente, pasado y futuro (lo que se esperaba). El tiempo del futuro es donde el joven resalta, ya que al morir a temprana edad dejó muchas acciones sin realizar, así que se permite lamentarse por la prematura muerte que impidió realizar tales hechos.

Al respecto, Manuel García García y Joaquín Gutiérrez Calderón (Menandro Rhétor, 1996) aluden a la propuesta de Soffel (1974), quien considera que este sistema es innovación de Menandro y su propósito es establecer una distinción de los tres géneros del discurso retórico mediante la contraposición entre el presente y el pasado, el cual es parte del tratamiento del tema de la muerte (p. 248).

Menandro Rhétor también acota que no sobrepase el discurso las ciento cincuenta líneas, debido a que "los que están en duelo no tengan que soportar una larga dilación ni una excesiva extensión en las palabras, en medio de la desgracia y el infortunio. La monodia debe 
ser siempre de estilo suelto” (p. 250). Así, este tipo procura no ser muy extenso, pero sí aprovechar el elogio como pretexto para realizar un lamento.

Si bien existe un tipo denominado basilikòs lógos (discurso imperial), este opera como encomio al emperador, figura de autoridad y poder en el Gobierno, en el de una amplificación convencional de las cualidades que debe tener un gobernante (p. 149), de modo que se aleja del aspecto fúnebre que impera en esta investigación.

Por su parte, desde la cultura romana se utiliza la laudatio funebris que remite a las exequias latinas. Cicerón, en Brutus (2010), apartado 62, destaca que los familiares de los fallecidos han guardado algunas laudationes como trofeos de honor y para el uso de estas con motivo de la muerte de otro miembro de la misma familia. Este acto podría ser útil ya fuera para recordar la memoria de las glorias de los antepasados de la familia o, de igual manera, para resaltar los orígenes nobles.

Con base en lo anterior, Millares Carlo (1995) cita, en efecto, que la laudatio funebris era realizada por familias nobles para exaltar las glorias de sus difuntos y debían representar un género especial y muy antiguo de elocuencia (p. 23). Sin embargo, este crítico también refiere a otra forma de expresión luctuosa, las neniae, definidas como cánticos fúnebres destinados a exaltar los méritos del algún personaje fallecido (p. 20).

La laudatio funebris, en este contexto, solía presentarse como un instrumento importante de propaganda de la familia del difunto porque va dirigida al pueblo, por esta razón se necesita la autorización del senado romano. Es un discurso pronunciado ante la asamblea del pueblo y en casos de familias adineradas se ejecutaban en el Foro.

Por un lado, Mantzilas (2017), en Lavdationes Mvliervm, señala como subcategorías del género la laudatio ad sepulcrum; laudatio pro rostris; laudatio privata pro contiene; 
laudatio publica (Durry, 2002); si era noble, se realizaba en el foro; si era menor, se daba en tumba (p. 298).

Por otro lado, Pepe (2015) remite el uso de la laudatio funebris en honor de la matrona en época antigua, circa s. IV a. C. (p. 181). Además, la autora cita como primer testimonio de laudatio funebris para una mujer de Quinto Lutacio Cátulo por la madre Popilia, tal como afirma Cicerón (p. 182). De igual manera, enumera, alrededor del s. I a. C., otras laudationes de este tipo muy frecuentes a partir de las fuentes historiográficas que señalan a César como ejemplo: Suetonio y Plutarco refieren la laudatio en honor de su tía Iulia, la esposa de Mario; Dión Casio recuerda la de su hija Iulia, esposa de Pompeyo (p. 183).

Asimismo, Pepe (2015) aclara que no era limitada por testimonios epigráficos a la urbs, pues se difundió en territorios de provincias imperiales (p. 184). La autora utiliza, en detalle, el rasgo más relevante de la laudatio para conceptualizarla, ya que explica cómo era definida pública porque debía ser pronunciada en el ámbito del público fúnebre como funeral decretado por senado y realizado por público.

Sobre cómo elaborar el elogio en la laudatio funebris es útil la célebre Rhetorica ad Herennium (1997), manual retórico del siglo I a. C., en donde se cita que para el elogio se utilizan los siguientes elementos: en primer lugar, las circunstancias externas al individuo, tales como el azar o la fortuna, que contemplan el linaje, la educación, la patria, la riqueza, las amistades, entre otros; a estas se suman los atributos físicos, las cualidades que la naturaleza concede al cuerpo, como la agilidad, la fuerza y belleza y la salud; por último, las cualidades morales, aquellas que dependen del juicio y la reflexión, como la sabiduría, el juicio, la reflexión, el valor y la moderación (Liber III, 10, pp. 181-182).

De igual manera, el De oratore (1991) de Cicerón recomienda: primero, bona fortuna (res externae); segundo, los hechos (res gestae); y tercero, las virtudes (Liber II). Quintiliano 
(1887, III, 7, 12-13), por su parte, recuerda que el género demostrativo, como tal, perteneció, según la costumbre de los romanos, también a los negocios debido a que la laudatio funebris dependía de los cargos que el sujeto hubiera tenido en la República (III, 7, 2).

Sumado a lo anterior, el rétor hispano nota que sobre las alabanzas de los hombres se dividen en los tiempos que precedieron y en los que vivieron, de modo que antes de considerar al sujeto se hace lo propio con sus padres, antepasados e, incluso, su patria (III, 7, 10). Asimismo, acota que al hombre se le alaba por los bienes del alma, del cuerpo y por los que están fuera de este (III, 7, 12).

Previo a concluir el apartado, vale destacar que la tradición de lamentarse por el fallecimiento de alguien ya databa desde el mundo griego en un contexto literario mediante el célebre treno en la épica, cuyos casos más representativos son las canciones fúnebres para Héctor y Patroclo en la Ilíada. Así, se debe considerar si los romanos hubieran sido los responsables de atribuirle a este lamento un carácter más pragmático que exhibiera las cualidades del difunto con el propósito de incrementar su prestigio en los años venideros.

Si bien la clave de cualquier encomio es ensalzar virtudes y rememorar hazañas, el caso fúnebre se concentra en dos elementos: a) ensalzar al difunto, b) ensalzar las hazañas de los antepasados. A continuación, el elogio fúnebre a Carlos III.

\section{Las exequias y el propósito pragmático textual: Carlos III}

\section{y la retórica del lamento}

El término "exequias" refiere a la práctica romana de celebrar honras fúnebres a sus ciudadanos. Cabe destacar que siempre su uso es en plural - exsequiae- y es válido como 
sinónimo de "honra fúnebre”. La palabra se compone por el prefijo -ex (de, desde, fuera de) y el verbo sequi (seguir), procedente del indoeuropeo *sekw, “seguir”.

Por su parte, un antecedente de procedencia latina está en la oratio funebris al Emperador Valentiniano de San Ambrosio, incluida en el texto:

Date manibus Sancta mysteria, pio réquiem eius poscamus affectu. Date Sacramenta caelestia, animam Imperatoris nostris oblationibus prosequamur. Extollite, populi, mecum manus in Sancta, ut eo saltem munere uicem eius meritis rependamus (Prefacio, p. 3).

El fin pragmático textual que tiene una laudatio funebris es aprovechar el deceso del fallecido para exponer sus principales logros y méritos, de manera que esto sustenta más el nombre de su familia y así el linaje es motivo de mención. En otras circunstancias, se procedía a realizarlas por el temor de alguna desgracia posterior sobre la familia, de modo que se hacían como parte de un acto de "renovación" de todos los rituales respectivos para despedir al difunto.

El caso de la Elegía 2 corresponde, en esta investigación, según la preceptiva retórica clásica, más a una monodia que a un epitafio o paramythētikós. Menandro Rhétor (1996) explica que comparten elementos y metodología, mas debe predominar uno de los tres esenciales, de manera que en el epitafio es el elogio del fallecido, en el paramythētikós la consolación y en la monodia el lamento. En este sentido, la monodia es lo que, por predominio temático, enlaza más con el genus elegía, pues este género se caracteriza por expresar, en otras situaciones, la queja o lamento ante situaciones adversas. La querimonia elegíaca, en este caso, tiene un trasfondo de fúnebre por el deceso de un monarca, tal como en la Antigüedad se caracterizó el trenon griego. La Elegia 2 reza: 
Cingite Cupressi nunc omnes tempora sentis,

Qui estis alumni almae Palladis absque mora.

Et certe absunt, si clarissima lumina Phoebi,

Circuitu Daphnes non redimire decet:

Folia non etenim erit illi uerna decorans [5]

Uulnere, flammanti lumine, cito dato.

Sed magnum nunc (heu!) lacrymarum fundite pontum.

Postmodo singultus sint Boreas in eo,

Certe uitrea labilis haec pyra congruit, illi

Qui studiorum tam doctus amator erat. [10]

Nanque Minervae, jungente illo, nisus ad aulam,

Inuidiam externam suggerit ista nimis.

Quis dabit ingenio jam confidenter Olympi

Calcar, ut ascendat culmina montis ita,

Numinis, a quo rerum ratio pendet, \& ese [15]

Cernat, \& admirans illius alta satis?

Plangite jam causam omnes, quia dico doloris

Atropos, en CAROLUM hoc tempore

saeua tulit.

Sed licet ingens planctus uocitet: occidit noster [20]

Cinthius, in Coelo, \& pectore uiuit ad huc.

En cuanto a la estructura típica del encomio, Aftonio ordenaba en primer lugar un proemio sobre el tema existente; en este caso se inicia el poema con una mención del acto 
fúnebre mediante la mención de cubrirse - cingite- las sienes -sentis- con el ciprés cupressi- (v. 1). El ciprés es una planta que desde el mundo griego connota la muerte. En el contexto latino, Plinio Maior lo destaca como signo fúnebre (XVI, 33). Así, la mención del “ciprés en las sienes" sí se relaciona con el tema.

Seguidamente, el autor del poema no sigue el modelo griego en cuanto al segundo elemento, puesto que no evoca el pueblo, patria o antepasados, sino que adelanta el siguiente paso: el de la educación, que abarca las ocupaciones, el dominio del arte y el respeto a las leyes, ejemplificado con la afirmación de ser alumno -alumni- de una nutricia Atenea Palladis- (v. 2).

El tercer aspecto que cita Aftonio, las acciones según espíritu, cuerpo o prudencia podría entreverse con la mención del "más ilustre a los ojos de Febo" (v. 3), pues el dios Febo es el propiciador de las artes, música y medicina, entre otras facultades. La mención está precedida del verbo absunt, conjugación en tercera persona plural modo indicativo y tiempo presente del verbo absum, "estar ausente". Este aspecto vincula al difunto, por un lado, con la aprobación divina de ciertas acciones que representa Febo y, por otro, su ausencia como elemento fúnebre y, a su vez, propicio para el lamento.

Si bien hay menciones de acciones que le hacen ilustre ante Febo, no hay, explícitamente, un detalle sobre estas; se carece de la cita de los hechos relevantes de la vida de Carlos III. Como ejemplo, basta con mirar el segundo apartado de este artículo, ya que el haber promovido tantas mejoras en su gobierno, edificaciones, e incluso aportes a los símbolos patrios, no fue detallado en el poema. Estos hechos pudieron argumentarse en los valores del espíritu.

Tampoco se hallan en el poema menciones más representativas sobre la nobleza de Carlos III. Parece que aquello destacado es la presencia mediante palabras claves de cierto 
eco con la cultura clásica: Palladis (v. 2), Phoebi (v. 3), Daphnes (v. 3), Boreas (v. 8), Minervae (v. 11), Atropos (v. 18). Estos términos evocan a deidades griegas, en su mayoría, otras con denominaciones latinas. Previamente se había mencionado Palladis, que evoca a Atenea y más adelante en el poema se cita Minervae, referencia a Minerva, diosa latina considerada como equivalencia de la Atenea griega.

La referencia de las deidades como Atenea, Minerva y Febo parece asumir el rol de vincular al difunto con cualidades. Empero, no se expresan claramente cuáles son esas cualidades. El aspecto elegíaco parece imperar por encima del encomiástico, tal como manifiesta el verso séptimo con la idea de derramar lágrimas como mares (v. 7) o que "el Boreas es sollozo en la aurora" (v. 8). El lamento predomina antes que la exposición de cualidades.

Al relacionar lo antedicho con las tres referencias míticas más relevantes, se destaca que existe un lamento por la muerte del rey, pero la argumentación pudo recurrir a un modelo ya conocido desde la época clásica y no es el caso. Si se vinculan a Apolo y Dafne (vv. 3-6) con Minerva (vv. 11-12) y Átropos, de quien se dice que se lleva a Carlos en tiempo violento (vv. 18-19), quedan algunas dudas de la eficacia que pudiera tener como elogio. El mito de Apolo y Dafne explica el origen del árbol de laurel, no el de ciprés. El laurel es símbolo de victoria, de manera que es extraña su presencia en un poema que lamente y no se jacte de victoria.

Se destacan los términos que aluden a la querimonia: a) cupressi; b) absum; c) uulnere; d) lacrymarum; e) pyra; f) lamentos (plango en plangite y planctus); con los que aluden a sus cualidades: a) doctus y studiorum; b) unión con Minerva (Palladis y iungente Minervae); c) ingenio. 


\section{Encomio y querimonia}

La laudatoria se mezcla con el lamento. La queja es parte de la muestra de inconformidad con el resultado, de ahí el lamento; la laudatoria recopila las acciones distinguidas y notables, aquellas que, precisamente, contribuyen a que se lamente, puesto que la estima por el difunto aumenta, a su vez, el lamento por su ausencia.

Si bien se procuró explicar el vínculo entre la elegía fúnebre y la retórica clásica, parece que hubo un cierto conocimiento de la cultura clásica, principalmente mediante la mitología, pero en cuanto a la estructura encomiástica de carácter fúnebre parece darse más una ruptura. Es decir, en cierta medida no se sigue el modelo tradicional o quizás se haya optado por recurrir solo al aporte mítico y mezclar este con el literario que ofrece la elegía.

No obstante, vale destacar que el poema utiliza imágenes llamativas en cuanto al aspecto luctuoso. El mito de Apolo y Dafne origina el laurel que representa la victoria, este hubiera sido más recurrente en un poema como los epinicios de Píndaro, pero está expuesto en un lamento por la muerte de un gobernante. Se cita, de manera apropiada, el ciprés, mas queda la incertidumbre del rol que pudiera darse entre este árbol y el mito de Dafne. La conjetura inicial sería pensar en la metamorfosis de la ninfa como un tipo de muerte, un hecho validado por la metamorfosis como categoría mítica.

En cuanto a la presencia de rasgos elegíacos, sin dudar estos son propios de la elegía comprendida a través de querimonia como el lamento por aquello que está ausente. Sobre la función pragmática, pareciera que la situación histórica se aprovecha para resaltar la desgracia que ocasiona la ausencia de Carlos III. 


\section{Conclusión}

La elegía se asemeja más a una monodia por características retóricas genéricas. Pesa más la expresión de lamento, querimonia, que la de consolación o de epitafio, el encomio más predominante entre los tipos fúnebres que se establecieron en la preceptiva clásica. No obstante, cabe destacar que la monodia es atribuida a los jóvenes, de modo que no sería el caso de Carlos III. Esto suscita un problema en cuanto a la clasificación del poema como monodia. La conjetura podría afirmar que existe una estrategia retórica de presentar a Carlos III como un "joven” a quien le quedaba aún mucho por realizar. Empero, la historia nos dice que murió ya de edad avanzada.

La monodia se debe pronunciar para jóvenes, no conviene con ancianos. ¿Qué sucede con Carlos III? Ergo, no hay seguimiento completo de la preceptiva clásica. Una ruptura o incluso, cierto tipo de vanguardia, podría considerarse. Desde otra óptica, es válido sugerir que se da un conocimiento de la retórica clásica, pero se innova retóricamente al realizar un

entremezclamiento de tres variables del discurso encomiástico de carácter fúnebre. La monodia, entre ellas, parecería ser la que predomina y el epitafio y la consolación son complementos.

\section{Referencias bibliográficas}

Anónimo. (1997). Rhetorica ad Herennium. Madrid, España: Gredos.

Aftonio, Hermógenes y Theón. (1991). Ejercicios de retórica. (Introducción, notas y traducción de María Dolores Reche Martínez). Madrid, España: Gredos.

Cicerón, M. T. (1991). De oratore. (Traducción de Marcelino Menéndez Pelayo). Madrid, España: Alianza Editorial. 
Cicerón, M. T. (2010). Brutus. (Introducción, traducción y notas de Manuel Mañas Núñez). Madrid, España: Alianza Editorial.

Durry, M. (2002). Éloge funèbre d'une matrone romaine (éloge dit de Turia). París, Francia: Les Belles-Lettres.

Mantzilas, D. (2017). Lavdationes Mvliervm: Lives and virtues of five excepcional women. Carpe diem, II(2), 297-338.

Menandro Rhétor. (1996). Dos tratados de retórica epidíctica. (Introducción de Fernando Gascó; traducción y notas de Manuel García García y Joaquín Gutiérrez Calderón). Madrid, España: Editorial Gredos.

Millares Carlo, A. (1995). Historia de la Literatura Latina. México D. F.: Fondo de Cultura Económica.

Pepe, C. (2015). La fama dopo il silenzio: celebrazione della donna e ritratti esemplari di bonae feminae nella laudatio funebris romana En C. Pepe, G. Moretti (Eds.), Le parole dopo la morte (pp. 179-222). Trento, Italia: Università degli Studi di Trento.

Quintiliano, M. F. (1887). Instituciones oratorias. Tomo I. (Traducción de Ignacio Rodríguez y Pedro Sandier). Madrid, España: Librería de la Viuda de Hernando y C.

Soffel, J. (1974). Die Regeln Menanders für die Leichenrede in ihre Tradition dargestellt, herausgegeben, übersetzt und kommentiert. Meisenheim, Alemania: Verlag Anton Hain. 